\title{
Proteomic analysis reveals that Placenta-specific 9 induces cell proliferation and motility programs in human bronchial epithelial cells
}

\section{Hai-Xia Wang}

Institute for Medical Biology

Xu-Hui Qin

Institute for Medical Biology

Jinhua Shen

Institute for Medical Biology

Qing-Hua Liu

Institute for Medical Biology

Yun-Bo Shi

National Institute of Child Health and Human Development

Lu Xue ( $\nabla$ sparkler830305@hotmail.com )

Institute for Medical Biology https://orcid.org/0000-0002-3213-7365

Research article

Keywords: Plac9, 16HBE, iTRAQ, cell proliferation, cell cycle, cell migration

Posted Date: July 8th, 2020

DOl: https://doi.org/10.21203/rs.3.rs-36924/v1

License: (1) This work is licensed under a Creative Commons Attribution 4.0 International License.

Read Full License 


\section{Abstract}

Background: Abnormal reprogramming of airway epithelium is a key cause of pulmonary diseases. The molecular mechanism underlying the abnormal reprogramming of airway epithelial cells (AECs) remains to be elucidated. Placenta-specific protein 9 (Plac9), a putative secretory protein, initially identified in placenta, has previously been shown to affect cell proliferation and motility in human embryonic hepatic cells.

Results: Interestingly, we found that Plac9 was repressed in lung cancers (LCs) compared to the corresponding normal tissues. We further investigated the role of Plac9 in human bronchial epithelial cells by constructing a stable Plac9-overexpressing cell line (16HBE-GFP-Plac9) and analyzing the effect of Plac9 on cellular protein composition by using an isobaric tag for relative and absolute quantification (iTRAQ) proteomic approach. By gene ontology (GO) and pathway analyses, we found that GO terms and pathways associated with cell proliferation, cell cycle progression, and cell motility/migration were significantly enriched among the proteins regulated by Plac9. Consistently, we observed that overexpression of Plac9 reduced cell proliferation and altered cell cycle progression. In addition, it also increased cell motility, including migration and invasion.

Conclusions: Our findings suggest that Plac9 inhibits cell proliferation through $\mathrm{S}$ phase arrest by altering cyclins/cyclin-dependent kinases (CDKs) and promotes cell motility likely via the concerted actions of cyclins, E-cadherin and vimentin, which may underlie Plac9-mediated abnormal human bronchial pathogenesis.

\section{Background}

World-wide, lung diseases are some of the most common medical problems which affect the whole respiratory systems including larynx, trachea, bronchi, lung, etc. [1-3]. Ranged from mild to severe, lung diseases include but not limit to asthma, bronchiectasis, bronchitis, chronic obstructive pulmonary disease (COPD), and lung cancers (LCs) [4-6]. Lung diseases affect millions of people and have become a major public health issue which leads to a social and economic burden for both individuals and the public [7-11]. It is important to find new and effective treatments and medications to help patients live longer and achieve a better quality of life [12-14].

While different lung diseases have different symptoms, a common feature in most lung diseases is the abnormal reprogramming of airway epithelium [15-23]. Airway epithelial cells (AEC) could contribute to the pathogenesis of airway diseases, especially asthma and COPD, by monitoring the external environment and equipping pattern recognition receptors to orchestrate innate immune response to potentially dangerous inhaled materials [15]. For examples, increased AEC apoptosis was observed in COPD [16]. Rhinovirus induces goblet cell hyperplasia in AEC via Notch signaling in COPD [17]. Fibroblastepithelial interactions may play an important role in the epithelial-mesenchymal transition (EMT) process in COPD [18]. AEC-derived cytokines are crucial to the pathobiology of asthma [19]. Airway epithelial 
barrier dysfunction contributes to disease progression in asthma [20]. Abnormal proliferation of epithelial cells in respiratory system can induce airway remodeling including thickened epithelium and lamina reticularis in severe asthma [21]. EMT is a critical cellular phenomenon regulating tumor metastases in LC $[22,23]$. Taken together, pathological processes involving proliferation, migration and apoptosis of AEC have been observed in airway remodeling, airway barrier dysfunction, and EMT in a number of respiratory diseases. However, the underlying molecular mechanisms are still unclear.

Placenta-specific 9 (Plac9) is a putative secretory protein, which was initially identified in human placenta $[24,25]$. In a previous study, we found that Plac9 could inhibit cell proliferation via altering cell cycle related proteins, phospho-c-Myc, cyclin B1, p21 $1^{\text {Waf/Cip1 }}$ and phospho-Histone H3 [25]. To investigate if Plac9 play a role in lung epithelial cell function and pathology, we searched public databases for Plac 9 and found reduced Plac9 expression in lung cancers. To systematically characterize the proteins that may be regulated by Plac9, we constructed a stable cell line to overexpress Plac9 in the human bronchial epithelial cell line 16HBE and analyzed the proteome by using an isobaric tag for relative and absolute quantification (iTRAQ) proteomic approach. Bioinformatics analyses suggest that overexpression of Plac9 in 16HBE alter cell physiological processes, especially cell proliferation, cell cycle and cell immigration. Consistently, we observed the Plac9 overexpressing stable cells have reduced cell proliferation, S-phase arrest, and increased cell migration and invasion. Our findings suggest that Plac 9 plays a pathological role in lung-associated diseases.

\section{Results}

\section{Plac9 expression is repressed in LCs}

To determine if Plac9 expression is associated with LC, we screened the Oncomine database and (www.oncomine.org). We observed that in three published LC cohorts (Hou Lung, Selamat Lung, Okayama Lung), the expression of Plac9 was significantly decreased in LC compared to paired normal tissues (Figure 1), implicating Plac9 might play a role in lung epithelial pathogenesis.

\section{Establishing a cell line stably expressing Plac9 in human bronchial epithelial cell line 16HBE}

To explore the role of Plac9 in human bronchial epithelial pathogenesis, we constructed a stable Plac 9 overexpressing cell line (16HBE-GFP-Plac9) by transfecting the lentiviral Plac9 vector, which expressed both GFP and Plac9 under the control of the constitutive CMV promoter, into the 16HBE cells and a control line (16HBE-GFP) stably expressed only GFP as previously described [25]. Figure 2A showed representative photo of the stable cell lines (16HBE-GFP-Plac9 and 16HBE-GFP). Further qRT-PCR and western blot analyses showed that the 16HBE-GFP-Plac 9 cells had a significantly increased mRNA and protein levels of Plac9 compared to the control 16HBE-GFP cells (Figure 2B\&C).

\section{iTRAQ analysis of Plac9-regulated proteins}


To investigate the changes in protein expressed due to Plac9 overexpression, iTRAQ quantitative proteomic technology was applied to analyze the protein samples from $16 \mathrm{HBE}-$ GFP-Plac9 and the control 16HBE-GFP cells. The MS proteomics data have been deposited to the ProteomeXchange Consortium (http://proteomecentral.proteomexchange.org) via the iProX partner repository [26] with the dataset identifier PXD019147. From the analyses of three replicates for each cell lines, 279,431 total spectra were generated, of which 125,694 spectra matched known peptides. Ultimately, a total of 69,296 peptide fragments were identified, among which 6,841 unique proteins were identified and quantified. The peptide/protein distribution-based ion score, molecular weight, isoelectric point, peptide length, protein sequence coverage, peptide count and ratio of expression levels between the two cell lines were analyzed and found to be consistent with a technically successful and reliable iTRAQ experiments (Figure S1). Taking a cutoff of $\geq \pm 1.2$ fold change and $<0.05 p$-values, 714 proteins were found to be significantly regulated in Plac9-overexpressing 16HBE cells (Table S1, also see the volcano volcano plot in Figure S2). Among them, 405 proteins were upregulated, while 309 proteins were downregulated (Table S1). Hierarchical cluster analysis of the regulated proteins in the three replicates of each cell line showed highly reproducible patterns (Figure $3 \mathrm{~A}$ ). The validity of the iTRAQ was independent confirmed by western blot analysis of two of the regulated proteins: Gap Junction Protein Delta 3 (GJD3) and Leucine Zipper Like Transcription Regulator 1 (LZTR1) (Figure 3B).

\section{Bioinformatics analyses of the Plac9 regulated proteins}

To gain insights into the functions of the proteins that were altered by Plac9 overexpression, the differentially expressed proteins were categorized into three groups (biological process, molecular function, and cellular component) on the basis of GO (Gene Ontology) analysis. The differentially expressed proteins covered a wide range of biological processes, molecular functions and cellular components, which could be classified into 26,15 , and 18 subcategory groups, respectively (Figure 4). Specifically, the largest group within the biological process category was that of cellular process (654/668), followed by single-organism process (612/668) and metabolic process (553/668), whereas binding (628/662) and catalytic activity (315/662) were the most common categories for molecular function. The cellular component functions of these proteins were mainly related to the cell $(675 / 685)$, organelles (651/685), membrane (463/685) and macromolecular complex (389/685). The top 30 enriched GO categories were listed in Table 2, and the total enriched GO categories were listed in Table S2. These results showed that the predominant functions of the differentially expressed proteins were cellular process, particularly cell migration.

To identify the regulated biological pathways in the Plac9-overexpressed 16HBE cell line, a KEGG pathway-based analysis was conducted for the differentially expressed proteins. We obtained 316 maps using the differentially expressed proteins, and the predictions for the most differentially expressed proteins suggest that they are involved in 20 pathways (Table 3), and all enriched KEGG pathways were listed in Table S3. It should be noted that RNA transport, RNA polymerase, mRNA surveillance pathway which regulated gene expression, and the cell adhesion molecules (CAMs) pathway, which regulated cell 
proliferation and migration were all involved, which indicated that overexpression of Plac9 might exhibit an influence on cell proliferation and migration.

To explore the above speculation further, the protein-protein interaction network was analyzed by using the publicly available program STRING and the results were shown in Figure S3 and Table S4. Totally 714 differentially expressed proteins determined from the ITRAQ experiment were analyzed using the molecular interaction tool and 587 interactive proteins were identified. Interestingly, among 587 proteins, $1 / 4$ proteins (138/587) were related to cell proliferation, cell cycle, cell motility (Figure 5 and Table S5), these protein interactions indicated that Plac 9 might play an important role in cellular process, especially cell proliferation, cell cycle, and cell migration. These results further support a potential role of Plac 9 on cell proliferation and cell motility.

\section{Effect of Plac9 on cellular processes including cell proliferation, cell cycle and cell migration}

To test the above predicated role of Plac9 in cell proliferation, MTT and colony formation assays were carried out with 16HBE-GFP-Plac9 and 16HBE-GFP cell lines. The MTT results showed that $16 \mathrm{HBE}-\mathrm{GFP}$ Plac9 cells exhibited a significantly decreased proliferative capacity compared with 16HBE-GFP cells (Figure 6A). Furthermore, in vitro colony formation assays demonstrated that the frequencies of colony formation of the 16HBE-GFP-Plac9 cells were statistically lower than those of the 16HBE-GFP cells (Figure 6B\&C). The results indicated that Plac9 plays an inhibiting role in $16 \mathrm{HBE}$ proliferation.

Based on iTRAQ data, CDK2, which was a key regulator of G1-S transition, was downregulated ( 0.9 fold, $p$ $<0.05)$. Consistently, flow cytometry showed that overexpressing Plac9 altered cell cycle distribution of $16 \mathrm{HBE}$ cells (Figure 7A\&B). The cells in $\mathrm{G} 1$ phase were reduced while those in the $S$ phase percentages significantly increased by Plac9 overexpression. Furthermore, western blot analysis showed proteins promoting cell cycle progression such as c-Myc, cyclin D3, cyclin E2, CDK2 and CDK4 were all decreased, while cell cycle inhibitors such as p2 $1^{\text {Waf/cip1 }}$, myt1 and were increased in Plac9-overexpressing cells Figure 7C). Meanwhile M-phase entry repressors including cyclin B1 and p-cdc2 were increased too. On the other hand, overexpressing Plac9 did not affect apoptosis (data not shown).

As indicated above, the iTRAQ data suggest that Plac9 affect cell migration. To test this experimentally, two cell motility assays (wound-healing and cell invasion) were utilized as previously described [27]. As shown in Figure 8A\&B, the wound-healing assay showed that wound closure for 16HBE-GFP-Plac9 was much faster than control group after $48 \mathrm{~h}$, indicating that Plac 9 overexpression strongly enhanced cell migration. Next, we used a Transwell ${ }^{\circledR}$ chamber for cell invasion assay (Figure 8C\&D). The numbers of invading Plac9 overexpression cell was found to be significantly higher in 16HBE-GFP-Plac9 cells compared to control cells. The results thus showed that overexpression of Plac 9 resulted in markedly increased cellular motility.

It is well known that E-cadherin, $\mathrm{N}$-cadherin, and vimentin, are key regulators of embryonic development, organ morphogenesis, and tumor growth $[28,29]$ and are also involved in epithelial cell motility via EMT [30-32]. In Plac9-overexpressing 16HBE cells, we found surprisingly that E-cadherin was expressed a 
significantly higher protein level compared to the control (Figure 8E) while Vimentin was inhibited in Plac9-overexpressing 16HBE cells. The expression of N-cadherin didn't show any change. Taken together, the results indicated that the overexpression of Plac9 facilitated cell motility despite increased E-cadherin expression and reduced vimentin.

\section{Discussion}

Abnormal physiological process of airway epithelium is one of the key symptoms of lung diseases. Here we have provided evidence for a role of a putative secretory protein, Plac9, in pathophysiology of human airway epithelial cells. First, we observed decreased expression of Plac9 in LCs from a public database. More importantly, our global proteomic analysis of Plac9 regulated proteins and cell culture studies support a role of Plac9 in inhibiting cell proliferation and promoting cell migration.

We used iTRAQ labeling quantitative proteomic technique to identify Plac9 regulated proteins. A total 714 regulated proteins were identified. Among them, about 1/4 proteins related to cell proliferation, cell cycle and cell motility. Consistently, MTT and colony formation experiments provided clear evidence that the overexpression of Plac 9 could inhibit cell proliferation. The result was consistent with that our previous study showing that Plac9 overexpression inhibits proliferation of human embryo liver cell line, L02 [25]. Furthermore, cell cycle distribution data showed that overexpression of Plac9 in 16HBE could increase $S$ phase population and a corresponding decrease of cells in the $\mathrm{G} 1$ phase. Mechanistically, Plac 9 appears to induce cell cycle arrest at $\mathrm{S}$ phase, by regulating the levels of cell cycle-associated proteins including cyclins and CDKs.

Cyclins and CDKs are pivotal for cell cycle progression [33]. Among them, cyclin D/CDK4 complexes and cyclin E/CDK2 complexes are critical factors for G1-S progression of the cell cycle [34]. Consistently, we found that in 16HBE-GFP-Plac9 cell line, downregulation of cyclin D3, cyclin E2, CDK2, CDK4 was associated with the accumulation of cells in $S$ phase, in agreement with earlier finding that $S$ phase arrest is associated with downregulation of cyclin D/CDK4 complex and cyclin E/CDK2 [35, 36].

Activation of Cyclin B1/cdc2 complex is a pivotal step of mitosis entry. This step is mediated principally by the dephosphorylation of cdc2 [37]. Myt1, a family member of the Wee kinase family, can phosphorylate cdc2 to prevent mitosis initiation [38]. In 16HBE-GFP-Plac9 cell line, the accumulation of $S$ phase cells was accompanied by the upregulation of p-cdc2, myt1 and Cyclin B1, suggesting that Plac9induced cdc2 phosphorylation prevents mitosis entry and facilitate $S$ phase arrest.

$\mathrm{p} 21^{\text {Waf } / \text { cip } 1}$ protein is a cell cycle inhibitor and plays an important role in cell growth arrest $[39,40]$. Protooncogene c-Myc could suppress p21 Waf1/cip1 expression, while downregulation of c-Myc could induce S phase arrest and inhibit cell proliferation [41, 42]. In 16HBE-GFP-Plac9 cell, c-Myc and its transcriptional target, p2 $1^{\text {Waf/cip } 1}$ were found to be down- and up-regulated, respectively, likely contributing to $S$ phase arrest and reduced cell proliferation. 
Taken together, these results indicated that Plac9 induced S phase arrest via the inactivation of cyclin E2/CDK2 and cyclin D3/CDK4 complexes, myt1-induced Cyclin B1/cdc2 phosphorylation and c-Myc down-regulation. The negative effect of Plac9 on the cell cycle progression suggests that Plac9 may be a potential tumor suppressor.

Our cell motility assays showed that overexpressed Plac9 could facilitate cell migration. Western blot showed that E-cadherin was upregulated in 16HBE-GFP-Plac9 cells while vimentin was downregulated. Normally, increased cell migration relies on loss of E-cadherin and acquisition of vimentin $[43,44]$. On the other hand, recent evidence suggest that besides classical cadherins, cell cycle proteins have several noncanonical roles in cell migration, in addition to their well-established functions in driving cell proliferation [45]. For instance, long non-coding RNA p53-inducible cancer-associated RNA transcript 1 (PICART1) stimulated cell migration in tumor cells via decreased c-Myc and increased p21 Waf/Cip1 [46]. High CDK2 activity could phosphorylates breast cancer metastasis suppressor 1 (BRMS1) then suppress cell migration [47]. Cell migration of BMAL1 (brain and muscle aryl hydrocarbon receptor nuclear translocator-like 1)-knockdown glioblastoma cells was elevated, accompanied with upregulation of cyclin B1 [48]. Taken together, Plac9 overexpression-induced cell motility probably relies on the coordination of

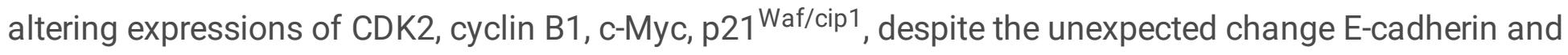
vimentin levels.

\section{Conclusions}

Our present study provides a global protein regulation profile underlying the molecular function of Plac 9 in human airway epithelium. Of the 714 different expressed proteins in Plac9-overexpressed 16HBE cell line, 1/4 were associated with cell proliferation, cell cycle and cell motility. Consistently, we provided experimental evidence to show that Plac9 inhibits cell proliferation, accompanied by S-phase arrest, and promoted cell migration. To our knowledge, this is the first study to investigate the mechanism of how Plac9 affects human bronchial epithelial cell proliferation and cell migration. Our findings suggest that Plac9 may be involved in lung diseases via regulating cell proliferation and migration.

\section{Methods}

\section{Cell culture and stable Placو-overexpressing clones}

Human bronchial epithelial cell line 16HBE was purchased from Shanghai Zhongqiaoxinzhou Biotech (Catalog Number: ZQ0001). 16HBE cells were cultured in Dulbecco's modified Eagle Medium (DMEM, Hyclone, Waltham, MA, USA) supplemented with $10 \%$ fetal bovine serum (FBS, ScienCell, San Diego, CA, USA) in $5 \% \mathrm{CO}_{2}$ at $37^{\circ} \mathrm{C}$. Stable Plac9-overexpressing cell line (16HBE-GFP-Plac9) and the corresponding stable control (16HBE-GFP) were custom-made by Genechem Co., Ltd, Shanghai, China.

\section{Protein preparation and digestion}


The cells were randomly pooled into three groups. The three replicates were treated for iTRAQ analysis to identify differentially expressed proteins as previously described with minor revision $[49,50]$. Each sample was sonicated for $15 \mathrm{~min}$ in $500 \mu \mathrm{L}$ SDT lysis buffer (4\% sodium dodecyl sulfate (SDS), $100 \mathrm{mM}$ Tris-HCl, pH 7.6). Samples were then incubated in water for $15 \mathrm{~min}$ at $95^{\circ} \mathrm{C}$ and centrifuged at $14,000 \times \mathrm{g}$ for $15 \mathrm{~min}$. The supernatant was collected, and protein concentration was determined with bicinchoninic acid (BCA) protein quantity method. Protein samples were then stored at $-80^{\circ} \mathrm{C}$ before further analyses. $30 \mu \mathrm{L}$ of protein mixtures was mixed with $1 \mathrm{M}$ dithiothreitol (DTT) at a final concentration of $100 \mathrm{mM}$, and then incubated in $95^{\circ} \mathrm{C}$ water bath for $5 \mathrm{~min}$. After cooling to room temperature, the sample was mixed with $200 \mu \mathrm{L}$ UA buffer (8 M urea and $150 \mathrm{mM}$ Tris - $\mathrm{HCl}, \mathrm{pH}$ 8.5), loaded onto an ultrafiltration filter (30-kDa cutoff, Sartorius, Germany), centrifuged at 12,500 $\times \mathrm{g}$ for $25 \mathrm{~min}$, and the filter was washed with UA buffer twice. Subsequently, $100 \mu \mathrm{L}$ of iodoacetamide solution ( $100 \mathrm{mM}$ iodoacetamide in UA buffer) was added to the filter, vortexed for $1 \mathrm{~min}$ at $600 \times \mathrm{rpm}$, incubated for $30 \mathrm{~min}$ at room temperature in the dark, and centrifuged at $12,500 \times \mathrm{g}$ for $25 \mathrm{~min}$. Filtrate was discarded. The filter were washed twice with $100 \mu \mathrm{L}$ UA buffer $(12,500 \times \mathrm{g}, 15 \mathrm{~min})$. Next, $100 \mu \mathrm{L}$ dissolution buffer (Applied Biosystems, Foster City, CA, USA) was added and centrifuged at $12,500 \times \mathrm{g}$ for $15 \mathrm{~min}$. This step was repeated twice. Then $40 \mu \mathrm{L}$ trypsin (Promega, Madison, WI, USA) buffer ( $5 \mu \mathrm{g}$ trypsin in $40 \mu \mathrm{L}$ dissolution buffer) was added to the filter and the filter was softly vortexed for $1 \mathrm{~min}$ at $600 \times \mathrm{rpm}$. The filter was incubated at $37^{\circ} \mathrm{C}$ for $16-18$ $\mathrm{h}$. The filter unit was transferred to a new tube and centrifuged at $12,500 \times \mathrm{g}$ for $15 \mathrm{~min}$. The digested peptides were collected with $20 \mu \mathrm{L}$ dissolution buffer and the peptide concentration was measured on a Nanodrop 2000 spectrophotometer (Thermo Scientific, Wilmington, DE, USA) at $280 \mathrm{~nm}$.

\section{ITRAQ labeling and analysis}

A total of $100 \mu \mathrm{g}$ peptide mixture was labeled with iTRAQ reagents according to manufacturer instructions (Applied Biosystems, Foster City, CA, USA). Triplicate 16HBE-GFP-Plac9 samples were labeled with reagent 114,115 , and 116 , respectively. Triplicate 16 HBE-GFP samples were labeled with reagent 117, 118, and 121, respectively. The labeled samples were mixed and fractioned on Agilent 1260 infinity II HPLC system (Agilent Technologies, Palo Alto, CA, USA). Buffer A consisted of $10 \mathrm{mM} \mathrm{HCOONH}_{4}, 5 \%$ $(\mathrm{v} / \mathrm{v})$ acetonitrile, $\mathrm{pH}$ 10.0; Buffer $\mathrm{B}$ consisted of $10 \mathrm{mM} \mathrm{HCOONH}_{4}, 85 \%(\mathrm{v} / \mathrm{v})$ acetonitrile, $\mathrm{pH}$ 10.0. The column was equilibrated with buffer $A$, and the samples were separated in $0 \%(v / v)$ buffer $B$ for 25 min, 0 - 7\% (v/v) buffer B for 5 min, 7 - 40\% (v/v) buffer B for 35 min, 40 - 100\% (v/v) buffer B for 5 min, and $100 \%(\mathrm{v} / \mathrm{v})$ buffer $B$ for $15 \mathrm{~min}$ at a flow rate of $1 \mathrm{~mL} / \mathrm{min}$. Approximate 36 samples were collected, lyophilized, dissolved with $0.1 \%$ formic acid (FA), and pooled into 10 fractions for further mass spectrometry analysis.

Each fraction was separated on Easy nLC system (Thermo Fisher Scientific, San Jose, CA, USA). Buffer C consisted of $0.1 \%(\mathrm{v} / \mathrm{v})$ formic acid in MilliQ water; buffer D was buffer $\mathrm{C}$ with $80 \%(\mathrm{v} / \mathrm{v})$ acetonitrile. Then samples were loaded via an autosampler onto the analytical column Acclaim ${ }^{\mathrm{TM}}$ PepMap $^{\mathrm{TM}} \mathrm{RSLC}$ $50 \mu \mathrm{m} \times 15 \mathrm{~cm}$, nano viper (Thermo Fisher Scientific, San Jose, CA, USA) and separated at $300 \mathrm{~nL} / \mathrm{min}$. 
Peptide analysis was performed on a Q-Exactive Plus mass spectrometer (Thermo Fisher Scientific, San Jose, CA, USA) in positive ion mode for 120 min, with a selected mass range of $350-1,800$ mass/charge $(\mathrm{m} / \mathrm{z})$. For the survey scan, a first-order mass spectrum resolving power was set to 70,000 , an automatic gain control (AGC) target value was $3 \mathrm{E} 6$, a first-order maximum ion injection (IT) time was $50 \mathrm{~ms}$. The $\mathrm{m} / \mathrm{z}$ ratios of polypeptide and polypeptide fragments were obtained according to the following methods: Ten-fragments mass spectrometry spectra (MS2) scan were collected after each full scan. The MS2 Activation Type was higher-energy collisional dissociation (HCD). The isolation window was $2 \mathrm{~m} / \mathrm{z}$. The second-order MS resolution was 17,500 with 1 microscan. The second-order Maximum IT time was 45 $\mathrm{ms}$. The normalized collision energy was $30 \mathrm{eV}$.

\section{Bioinformatics and multivariate analyses}

The raw data of the mass spectrometry (MS) analysis were derived from RAW files. Database searches and quantitative analyses were performed by using Mascot 2.6 and Proteome Discoverer 2.1 (Thermo Fisher Scientific, San Jose, CA, USA). For protein-abundance ratios measured using iTRAQ, a 1.2-fold change between two sample groups was set as the threshold and a relative quantification $p$-value below 0.05 were regarded as being differentially expressed. The database (Uniprot_HomoSapiens_161584_20180123) was downloaded from UniProt website (http://www.uniprot.org) on 2018-01-23. The localized sequence alignment software NCBI Basic Local Alignment Search Tool (BLAST 2.2.28+-win32.exe; http://blast.ncbi.nlm.nih.gov/Blast.cgi) was used to perform sequence alignment between the identified proteins and protein sequences in the UniProt database. The mapping function of Blast2GO Command Line (www.geneontology.org; version go_201504.obo) was used to extract GO function entries correlated with the aligned sequences for all differentially expressed proteins. The Kyoto Encyclopedia of Genes and Genomes (KEGG) Automatic Annotation Server (KAAS; http://www.genome.jp/tools/kaas/) was used to align target proteins in the KEGG GENES database [51]. The heatmap was visualized by the online ClustVis tool

(https://biit.cs.ut.ee/clustvis/) [52]. The network of protein-protein interactions was mapped using the online STRING 10.5 tool (http://string-db.org).

\section{Reverse transcription and quantitative real-time PCR (RT-qPCR)}

The mRNA levels were determined with quantitative real-time PCR analysis by using a QuantStudio ${ }^{\circledR} 5$ Real-Time PCR System (Applied Biosystems, Foster City, CA, USA) according to the manufacturer's instructions. Briefly, total RNA was extracted from cells by using an RNA extraction kit (Bioteke, Beijing, China) and cDNA was synthesized by using a cDNA synthesis kit (Thermo Fisher Scientific, San Jose, CA, USA). Then $5 \mathrm{ng}$ CDNA was amplified with indicated primers (Table 1) in SYBR Green Real-time PCR Master Mix (Toyobo, Osaka, Japan). The PCR cycle was: $95^{\circ} \mathrm{C}$ for $30 \mathrm{sec}, 45 \mathrm{cycles}$ of $95^{\circ} \mathrm{C}$ for $5 \mathrm{sec}$, and $60^{\circ} \mathrm{C}$ for $30 \mathrm{sec}$. The PCR amplification was followed by melting curve analysis by using the defaulted program of the QuantStudio ${ }^{\circledR} 5$ Real-Time PCR machine (Thermo Fisher Scientific, San Jose, CA, USA). The mRNA expression levels of indicated genes were calculated relative to Glyceraldehyde 3-phosphate dehydrogenase (GAPDH, internal control) using the $2^{-\Delta \Delta \mathrm{Ct}}$ method. 


\section{MTT assay and colony formation}

Cells were treated with 3-(4,5-Dimethylthiazol-2-yl)-2,5-diphenyltetrazolium bromide (MTT, Sigma, St Louis, MO, USA) for cell proliferation assay as described [25,53]. Briefly, the cells were cultured by seeding 1,000 cells/well into a 96-well tissue culture plate. Then $20 \mu \mathrm{L}$ MTT reagents were added to each well for $4 \mathrm{~h}$ at $37^{\circ} \mathrm{C}$. After adding $200 \mu \mathrm{L}$ dimethyl sulfoxide (DMSO) for each well, absorbance was

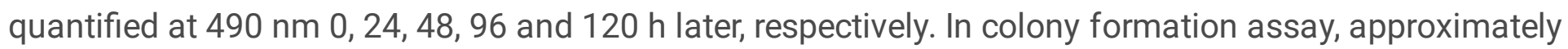
800 cells were plated and cultured in 6 -well plates, then fixed with ethanol and stained with $0.5 \%$ crystal violet 2 weeks later. The colonies were photographed and quantified.

\section{Flow cytometer analysis}

This was performed similarly as previously described $[25,53]$. Briefly, approximately $10^{6} 16 \mathrm{HBE}$ cells were pelleted and fixed with $70 \%$ ethanol for 1 hour at $4{ }^{\circ} \mathrm{C}$. After resuspending with staining buffer $(2 \mathrm{mg} / \mathrm{mL}$ propidium iodide $(\mathrm{PI}): 10 \mathrm{mg} / \mathrm{mL}$ RNase: $1 \times$ phosphate buffered saline $(\mathrm{PBS})=25: 10: 1000)$, the cell cycle distribution was assessed using a BD FACS Calibur Flow Cytometer (BD Biosciences, San Jose, CA, USA) according to the manufacturer's instructions. For the apoptosis assay, approximately $10^{6} 16 \mathrm{HBE}$ cells were harvested, resuspended and labeled with fluorescein isothiocyanate (FITC)-Annexin V and PI in the dark at room temperature for 15 min. Apoptotic cells were analyzed using a BD FACS Calibur Flow Cytometer according to manufacturer's instructions.

\section{Wound-healing and invasion assays}

Wound-healing and invasion assays were performed as reported [54]. $4 \times 10^{5} 16 \mathrm{HBE}-\mathrm{GFP}$-Plac 9 or 16HBE-GFP clones per well were seeded in a 12-well plate with complete medium (DMEM containing 10\% FBS). After growing to $90 \%$ confluence, a wound was created by scraping the cell layer with a sterile pipette tip. After wounding, floating cells were removed by replacing the culture medium. Digital images of the wounds were photographed at 0,12 and $24 \mathrm{~h}$, respectively. The healing rate (100\%) at different time point was calculated by comparing the recovered wound width with the starting wound width.

For cell invasion assay, $2 \times 10^{5} 16 \mathrm{HBE}-\mathrm{GFP}-$ Plac 9 or $16 \mathrm{HBE}-\mathrm{GFP}$ cells per well in $100 \mu \mathrm{L}$ medium (DMEM supplemented with $1 \%$ FBS) were seeded in the top chambers of 24 -well transwell plates $(8.0 \mu \mathrm{m}$, pore size; Corning Costar, Corning, NY, USA), and DMEM supplemented with $10 \%$ FBS was added to the bottom chamber. Cell were maintained at $37^{\circ} \mathrm{C}$ for $48 \mathrm{~h}$. Then the cells on the top side of the filter were wiped out with a cotton swab, while those on the bottom side (migrated) were fixed with $4 \%$ polyoxymethylene, stained with a Giemsa staining solution (Yeasen, Shanghai, China) to visualize the cells and photographed. Five randomly selected fields per well were photographed. The numbers of cells in 5 random fields per well were counted.

\section{Western blot analysis}


Cells were collected and lysed in protein lysis buffer (Beyotime, Shanghai, China) supplemented with PMSF (Beyotime, Shanghai, China) and protease inhibitor cocktail (Bimake, Houston, TX, USA). Proteins samples (20 $\mathrm{\mu g}$ per lane) were separated on SDS-10\% polyacrylamide gel electrophoresis (PAGE) and transferred to nitrocellulose (NC) membranes. The membranes were blocked with $5 \%$ nonfat dry milk and incubated with indicated antibodies (Cell Signaling Technology, Beverly, MA, USA) to detected the corresponding proteins by following the manufacturer's instructions. The bands were visualized by the ECLÔ reagents (Thermo Fisher Scientific, San Jose, CA, USA). b-actin was employed as an internal control.

\section{Statistical analysis}

Differences between groups were analyzed for statistical significance by using a student's t-test. GO or KEGG enrichment analyses were performed using a Fisher's Exact Test. All experiments were repeated at least three times. Results were expressed as means \pm Standard deviation (SD). $p<0.05$ represents significantly different.

\section{List Of Abbreviations}

AEC, Airway epithelial cells; AGC, automatic gain control; BCA, bicinchoninic acid; BMAL1, brain and muscle aryl hydrocarbon receptor nuclear translocator-like 1; BRMS1, breast cancer metastasis suppressor 1; CDK, cyclin-dependent kinase; COPD, chronic obstructive pulmonary disease; DMEM, Dulbecco's modified Eagle Medium; DMSO, dimethyl sulfoxide; EMT, epithelial-mesenchymal transition; FA, formic acid; FBS, fetal bovine serum; FITC, fluorescein isothiocyanate; GAPDH, Glyceraldehyde 3phosphate dehydrogenase; GJD3, Gap Junction Protein Delta 3; GO, gene ontology; HCD, higher-energy collisional dissociation; IT, ion injection; ITRAQ, isobaric tag for relative and absolute quantification; KAAS, KEGG Automatic Annotation Server; KEGG, Kyoto Encyclopedia of Genes and Genome; LCs, lung cancers; LZTR1; Leucine Zipper Like Transcription Regulator 1; MS, mass spectrometry; MS2, mass spectrometry spectra; MTT, 3-(4,5-Dimethylthiazol-2-yl)-2,5-diphenyltetrazolium bromide; NC, nitrocellulose; PAGE, polyacrylamide gel electrophoresis; PBS, phosphate buffered saline; PI, propidium iodide; Plac9, Placenta-specific protein 9; RT-qPCR, quantitative real-time PCR; SD, standard deviation; SDS, sodium dodecyl sulfate;

\section{Declarations}

\section{Ethics approval and consent to participate}

Not applicable.

\section{Consent for publication}

Not applicable. 
Availability of data and material

All data generated and analyzed in this study are available upon reasonable request from the corresponding author.

\section{Competing interests}

No competing financial interests exist.

\section{Funding}

This project was supported by Fund for Key Laboratory Construction of Hubei Province (Grant No. 2018BFC360), the National Natural Science Foundation of China (Grant No. 31101047 to LX), the Natural Science Foundation of Hubei Province, China (Grant No. 2018CFB594 to LX) and the China Scholarship Council (grant number 201808420069 to LX). YBS was supported by the intramural program of NICHD, $\mathrm{NIH}$, USA. The funding body had no role in the design of the study and collection, analysis, and interpretation of data or in writing the manuscript.

\section{Authors' contributions}

JS, QHL, YS and LX, conceived and designed the experiments. XHQ and HXW performed the experiments. $X H Q, H X W$ and $L X$ analyzed the data and generated the figures. LX and YS wrote the manuscript. All authors gave final approval for the submitted version.

\section{Acknowledgements}

The authors thank Genechem Co. and all the colleagues in Institute for Medical Biology for their technical support.

\section{References}

1. Brenner DR, McLaughlin JR, Hung RJ: Previous lung diseases and lung cancer risk: a systematic review and meta-analysis. PloS one 2011, 6(3):e17479.

2. Schluger NW, Koppaka R: Lung disease in a global context. A call for public health action. Annals of the American Thoracic Society 2014, 11(3):407-416.

3. Celli BR, Decramer M, Wedzicha JA, Wilson KC, Agusti A, Criner GJ, MacNee W, Make BJ, Rennard SI, Stockley RA et al: An Official American Thoracic Society/European Respiratory Society Statement: Research questions in chronic obstructive pulmonary disease. American journal of respiratory and critical care medicine 2015, 191(7):e4-e27.

4. Couraud S, Zalcman G, Milleron B, Morin F, Souquet PJ: Lung cancer in never smokers-a review. European journal of cancer 2012, 48(9):1299-1311. 
5. Vogelmeier CF, Criner GJ, Martinez FJ, Anzueto A, Barnes PJ, Bourbeau J, Celli BR, Chen R, Decramer $M$, Fabbri LM et al: Global Strategy for the Diagnosis, Management and Prevention of Chronic Obstructive Lung Disease 2017 Report: GOLD Executive Summary. Respirology 2017, 22(3):575-601.

6. Papaiwannou A, Zarogoulidis P, Porpodis K, Spyratos D, Kioumis I, Pitsiou G, Pataka A, Tsakiridis K, Arikas S, Mpakas A et al: Asthma-chronic obstructive pulmonary disease overlap syndrome (ACOS): current literature review. Journal of thoracic disease 2014, 6 Suppl 1:S146-151.

7. Burney $\mathrm{P}$, Jarvis $\mathrm{D}$, Perez-Padilla R: The global burden of chronic respiratory disease in adults. The international journal of tuberculosis and lung disease : the official journal of the International Union against Tuberculosis and Lung Disease 2015, 19(1):10-20.

8. Ferkol T, Schraufnagel D: The global burden of respiratory disease. Annals of the American Thoracic Society 2014, 11(3):404-406.

9. Grant CC, Wall CR, Gibbons MJ, Morton SM, Santosham M, Black RE: Child nutrition and lower respiratory tract disease burden in New Zealand: a global context for a national perspective. Journal of paediatrics and child health 2011, 47(8):497-504.

10. Shi T, McAllister DA, O'Brien KL, Simoes EAF, Madhi SA, Gessner BD, Polack FP, Balsells E, Acacio S, Aguayo $C$ et al: Global, regional, and national disease burden estimates of acute lower respiratory infections due to respiratory syncytial virus in young children in 2015: a systematic review and modelling study. Lancet 2017, 390(10098):946-958.

11. Zar HJ, Ferkol TW: The global burden of respiratory disease-impact on child health. Pediatric pulmonology 2014, 49(5):430-434.

12. Weiss DJ: Concise review: current status of stem cells and regenerative medicine in lung biology and diseases. Stem cells 2014, 32(1):16-25.

13. Tay TR, Abramson MJ, Hew M: Closing the million patient gap of uncontrolled asthma. The Medical journal of Australia 2016, 204(6):216-217.

14. Huang K, Wang C: Strengthen national action for the prevention and control of chronic respiratory diseases. Chinese medical journal 2014, 127(1):1-3.

15. Holtzman MJ, Byers DE, Alexander-Brett $\mathrm{J}$, Wang $\mathrm{X}$ : The role of airway epithelial cells and innate immune cells in chronic respiratory disease. Nature reviews Immunology 2014, 14(10):686-698.

16. Hodge S, Hodge G, Holmes M, Reynolds PN: Increased airway epithelial and T-cell apoptosis in COPD remains despite smoking cessation. The European respiratory journal 2005, 25(3):447-454.

17. Jing Y, Gimenes JA, Mishra R, Pham D, Comstock AT, Yu D, Sajjan U: NOTCH3 contributes to rhinovirus-induced goblet cell hyperplasia in COPD airway epithelial cells. Thorax 2019, 74(1):18-32.

18. Nishioka M, Venkatesan N, Dessalle K, Mogas A, Kyoh S, Lin TY, Nair P, Baglole CJ, Eidelman DH, Ludwig MS et al: Fibroblast-epithelial cell interactions drive epithelial-mesenchymal transition differently in cells from normal and COPD patients. Respiratory research 2015, 16:72.

19. Mitchell PD, O'Byrne PM: Biologics and the lung: TSLP and other epithelial cell-derived cytokines in asthma. Pharmacology \& therapeutics 2017, 169:104-112. 
20. Sweerus K, Lachowicz-Scroggins M, Gordon E, LaFemina M, Huang X, Parikh M, Kanegai C, Fahy JV, Frank JA: Claudin-18 deficiency is associated with airway epithelial barrier dysfunction and asthma. The Journal of allergy and clinical immunology 2017, 139(1):72-81 e71.

21. Cohen L, E X, Tarsi J, Ramkumar T, Horiuchi TK, Cochran R, DeMartino S, Schechtman KB, Hussain I, Holtzman MJ et al: Epithelial cell proliferation contributes to airway remodeling in severe asthma. American journal of respiratory and critical care medicine 2007, 176(2):138-145.

22. Serresi M, Gargiulo G, Proost N, Siteur B, Cesaroni M, Koppens M, Xie H, Sutherland KD, Hulsman D, Citterio E et al: Polycomb Repressive Complex 2 Is a Barrier to KRAS-Driven Inflammation and Epithelial-Mesenchymal Transition in Non-Small-Cell Lung Cancer. Cancer cell 2016, 29(1):17-31.

23. Xu J, Zhao X, He D, Wang J, Li W, Liu Y, Ma L, Jiang M, Teng Y, Wang Z et al: Loss of EGFR confers acquired resistance to AZD9291 in an EGFR-mutant non-small cell lung cancer cell line with an epithelial-mesenchymal transition phenotype. Journal of cancer research and clinical oncology 2018, 144(8):1413-1422.

24. Galaviz-Hernandez C, Stagg C, de Ridder G, Tanaka TS, Ko MS, Schlessinger D, Nagaraja R: Plac8 and Plac9, novel placental-enriched genes identified through microarray analysis. Gene 2003, 309(2):81-89.

25. Ouyang C, Pu YZ, Qin XH, Shen J, Liu QH, Ma L, Xue L: Placenta-specific 9, a putative secretory protein, induces $\mathrm{G} 2 / \mathrm{M}$ arrest and inhibits the proliferation of human embryonic hepatic cells. Bioscience reports 2018, 38(6).

26. Ma J, Chen T, Wu S, Yang C, Bai M, Shu K, Li K, Zhang G, Jin Z, He F et al: iProX: an integrated proteome resource. Nucleic acids research 2019, 47(D1):D1211-D1217.

27. Hu HM, Chen Y, Liu L, Zhang CG, Wang W, Gong K, Huang Z, Guo MX, Li WX, Li W: C1orf61 acts as a tumor activator in human hepatocellular carcinoma and is associated with tumorigenesis and metastasis. FASEB J 2013, 27(1):163-173.

28. Mendonsa AM, Na TY, Gumbiner BM: E-cadherin in contact inhibition and cancer. Oncogene 2018, 37(35):4769-4780.

29. Kim NG, Koh E, Chen X, Gumbiner BM: E-cadherin mediates contact inhibition of proliferation through Hippo signaling-pathway components. Proceedings of the National Academy of Sciences of the United States of America 2011, 108(29):11930-11935.

30. Korpal M, Lee ES, Hu G, Kang Y: The miR-200 family inhibits epithelial-mesenchymal transition and cancer cell migration by direct targeting of E-cadherin transcriptional repressors ZEB1 and ZEB2. $J$ Biol Chem 2008, 283(22):14910-14914.

31. Maretzky T, Reiss K, Ludwig A, Buchholz J, Scholz F, Proksch E, de Strooper B, Hartmann D, Saftig P: ADAM10 mediates E-cadherin shedding and regulates epithelial cell-cell adhesion, migration, and beta-catenin translocation. Proceedings of the National Academy of Sciences of the United States of America 2005, 102(26):9182-9187.

32. Canel M, Serrels A, Frame MC, Brunton VG: E-cadherin-integrin crosstalk in cancer invasion and metastasis. Journal of cell science 2013, 126(Pt 2):393-401. 
33. Lim S, Kaldis P: Cdks, cyclins and CKls: roles beyond cell cycle regulation. Development 2013, 140(15):3079-3093.

34. Stamatakos M, Palla V, Karaiskos I, Xiromeritis K, Alexiou I, Pateras I, Kontzoglou K: Cell cyclins: triggering elements of cancer or not? World J Surg Oncol 2010, 8:111.

35. Wolter F, Akoglu B, Clausnitzer A, Stein J: Downregulation of the cyclin D1/Cdk4 complex occurs during resveratrol-induced cell cycle arrest in colon cancer cell lines. J Nutr 2001, 131(8):2197-2203.

36. Wang Y, Compton C, Rankin GO, Cutler SJ, Rojanasakul Y, Tu Y, Chen YC: 3-Hydroxyterphenyllin, a natural fungal metabolite, induces apoptosis and $\mathrm{S}$ phase arrest in human ovarian carcinoma cells. Int J Oncol 2017, 50(4):1392-1402.

37. Zhou BB, Elledge SJ: The DNA damage response: putting checkpoints in perspective. Nature 2000, 408(6811):433-439.

38. Booher RN, Holman PS, Fattaey A: Human Myt1 is a cell cycle-regulated kinase that inhibits Cdc2 but not Cdk2 activity. J Biol Chem 1997, 272(35):22300-22306.

39. Abbas T, Dutta A: p21 in cancer: intricate networks and multiple activities. Nat Rev Cancer 2009, 9(6):400-414.

40. Huang YQ, Li JJ, Karpatkin S: Thrombin inhibits tumor cell growth in association with up-regulation of p21(waf/cip1) and caspases via a p53-independent, STAT-1-dependent pathway. $\mathrm{J}$ Biol Chem 2000, 275(9):6462-6468.

41. Gurung SK, Dana S, Mandal K, Mukhopadhyay P, Mondal N: Downregulation of c-Myc and p21 expression and induction of $S$ phase arrest by naphthalene diimide derivative in gastric adenocarcinoma cells. Chem Biol Interact 2019, 304:106-123.

42. Dorasamy MS, Choudhary B, Nellore K, Subramanya H, Wong PF: Dihydroorotate dehydrogenase Inhibitors Target c-Myc and Arrest Melanoma, Myeloma and Lymphoma cells at S-phase. J Cancer 2017, 8(15):3086-3098.

43. Niessen CM, Leckband D, Yap AS: Tissue organization by cadherin adhesion molecules: dynamic molecular and cellular mechanisms of morphogenetic regulation. Physiol Rev 2011, 91(2):691-731.

44. Mclnroy L, Maatta A: Down-regulation of vimentin expression inhibits carcinoma cell migration and adhesion. Biochem Biophys Res Commun 2007, 360(1):109-114.

45. Hydbring P, Malumbres M, Sicinski P: Non-canonical functions of cell cycle cyclins and cyclindependent kinases. Nat Rev Mol Cell Biol 2016, 17(5):280-292.

46. Cao Y, Lin M, Bu Y, Ling H, He Y, Huang C, Shen Y, Song B, Cao D: p53-inducible long non-coding RNA PICART1 mediates cancer cell proliferation and migration. Int J Oncol 2017, 50(5):1671-1682.

47. Caldon CE: Cdk2 regulates metastasis suppressor BRMS1. Cell Cycle 2016, 15(6):779-780.

48. Gwon DH, Lee WY, Shin N, Kim SI, Jeong K, Lee WH, Kim DW, Hong J, Lee SY: BMAL1 Suppresses Proliferation, Migration, and Invasion of U87MG Cells by Downregulating Cyclin B1, Phospho-AKT, and Metalloproteinase-9. Int J Mol Sci 2020, 21(7). 
49. Yang Y, Zheng N, Zhao X, Zhang Y, Han R, Ma L, Zhao S, Li S, Guo T, Wang J: Proteomic characterization and comparison of mammalian milk fat globule proteomes by iTRAQ analysis. Journal of proteomics 2015, 116:34-43.

50. Lang X, Wan Z, Pan Y, Bu Z, Wang X, Wang X, Ji X, Zhu L, Wan J, Sun Y et al: Catabolite control protein $A$ has an important role in the metabolic regulation of Streptococcus suis type 2 according to iTRAQ-based quantitative proteomic analysis. Molecular medicine reports 2015, 12(4):5967-5972.

51. Moriya $Y$, Itoh M, Okuda S, Yoshizawa AC, Kanehisa M: KAAS: an automatic genome annotation and pathway reconstruction server. Nucleic acids research 2007, 35(Web Server issue):W182-185.

52. Metsalu T, Vilo J: ClustVis: a web tool for visualizing clustering of multivariate data using Principal Component Analysis and heatmap. Nucleic acids research 2015, 43(W1):W566-570.

53. Qin XH, Wang HX, Ma L, Shen J, Liu QH, Xue L: Knockout of the Placenta Specific 8 Gene Affects the Proliferation and Migration of Human Embryonic Kidney 293T Cell. Cell Biochem Biophys 2019.

54. Qin XH, Wang HX, Ma L, Shen J, Liu QH, Xue L: Knockout of the Placenta Specific 8 Gene Affects the Proliferation and Migration of Human Embryonic Kidney 293T Cell. Cell Biochem Biophys 2020, 78(1):55-64.

\section{Tables}

Table 1. Sequences of primers used for Real-Time PCR

\begin{tabular}{lll}
\hline Primer name & Sequences & Product sizes (bp) \\
\hline Plac9-F & ATGGAGGAGATGGTAGAGAAGAC $241 \mathrm{bp}$ \\
Plac9-R & CACATGAAGCTAAGGAAGGAAGT & \\
GAPDH-F & TGACTTCAACAGCGACACCCA & $121 \mathrm{bp}$ \\
GAPDH-R & CACCCTGTTGCTGTAGCCAAA & \\
\hline
\end{tabular}

Table 2. Top 30 enriched GO terms among the differentially expressed proteins. $\mathrm{P}$ represents biological process. C represents cellular component. F represents molecular function. \#DIFF represents the number of differentially expressed proteins involved in certain GO term. \%DIFF represents the ratio of \#DIFF to the total differentially expressed proteins. The data was sorting by FDR. 
GO:0032502

GO:0044767

GO:0048869

GO:0048856

GO:0048731

GO:0042221

GO:0048513

GO:0009888

GO:0006952

GO:0048646

GO:0022613

GO:0030154

GO:0009605

GO:0004872

GO:0060089

GO:0007275

GO:0032501

GO:0006954

GO:0042254

GO:0044707

GO:0000786

GO:0050793

GO:0051240

GO:0065008

GO:0050691

GO:0035425

GO:0006955

GO:0071944

GO:0016477

GO:0051239 developmental process

single-organism developmental process

cellular developmental process

anatomical structure development

system development

response to chemical

animal organ development

tissue development

defense response

anatomical structure formation involved in morphogenesis

ribonucleoprotein complex biogenesis

cell differentiation

response to external stimulus

receptor activity

molecular transducer activity

multicellular organism development

multicellular organismal process

inflammatory response

ribosome biogenesis

single-multicellular organism process

nucleosome

regulation of developmental process

positive regulation of multicellular organismal process

regulation of biological quality

regulation of defense response to virus by host

autocrine signaling

immune response

cell periphery

cell migration

regulation of multicellular organismal process
424

410

57.42

316

44.26

394

55.18

345

48.32

338

47.34

280

39.22

190

26.61

164

22.97

110

15.41

28

3.92

298

41.74

199

27.87

8.40

F

$\mathrm{P}$

60

8.40

60

51.40

367

60.08

429

8.26

59

2.52

18

399

55.88

C

13

1.82

212

29.69

$149 \quad 20.87$

317

44.40

$\mathrm{P}$

39

5.46

P

1.26

P

21.29

C

152

40.34

$\mathrm{P}$

288

$145 \quad 20.31$

P
$234 \quad 32.77$ 
Table 3. Top 20 enriched KEGG pathways among the differentially expressed proteins. Up and down arrows indicated increased and decrease levels in Plac9-overexpressed 16HBE cell line compared to the GFP-16HBE cell line, respectively. 


\begin{tabular}{|c|c|c|}
\hline MapID & MapName & Differentially expressed proteins \\
\hline ko05322 & $\begin{array}{l}\text { Systemic lupus } \\
\text { erythematosus }\end{array}$ & $\begin{array}{l}\uparrow \text { HIST3H3, HIST1H3A, HIST2H2AB, HIST2H3PS2, } \\
\text { H3F3A, HIST1H3D, H2AFX, FLJ94402, HIST1H4A } \\
\downarrow \text { ACTN1, HEL-S-62p, ACTN4, C9 }\end{array}$ \\
\hline ko05146 & Amoebiasis & $\begin{array}{l}\uparrow \text { SERPINB3, SERPINB4, SERPINB13, SERPINB9, } \\
\text { SERPINB6, PRKACA, PIK3CB } \\
\downarrow \text { FN1, ACTN1, LAMB3, LAMC2, LAMA3, ACTN4, C9 }\end{array}$ \\
\hline ko03013 & RNA transport & \\
\hline ko03010 & Ribosome & $\begin{array}{l}\downarrow \text { EEF1A2, NUP210L, TACC3 } \\
\uparrow \text { MRPL23, MRPL10 } \\
\downarrow \text { MRPS14 }\end{array}$ \\
\hline ko05034 & Alcoholism & $\begin{array}{l}\uparrow \text { HIST3H3, HIST1 H3A, HIST2H2AB, HIST2H3PS2, } \\
\text { H3F3A, HIST1 H3D, H2AFX, Histone H2B, GNAI3, } \\
\text { HIST1H4A, } \\
\downarrow \text { P36873, HDAC }\end{array}$ \\
\hline ko04610 & $\begin{array}{l}\text { Complement and } \\
\text { coaqulation cascades }\end{array}$ & $\begin{array}{l}\uparrow \text { CLU, SERPINB2, SERPINE1 } \\
\text { HEL-S-62p RAB1A C9 F3 }\end{array}$ \\
\hline ko04260 & $\begin{array}{l}\text { Cardiac muscle } \\
\text { contraction }\end{array}$ & $\begin{array}{l}\uparrow \text { COX6A1, COX2, COX5B, COX7C, COX6B1, COX7A2 } \\
\downarrow \text { TPM4 HEL-S-265, TPM1 }\end{array}$ \\
\hline ko00240 & Pyrimidine metabolism & $\begin{array}{l}\text { } \text { POLR3K, POLR2I, TP, POLA2, FLJ92093, RNAP, } \\
\text { POLR2L, NT5C3B } \\
\text { ¿CANT1, UPP1, POLR2G, FLJ54187, UPRT, HCG23833, } \\
\text { UCK2, NT5E }\end{array}$ \\
\hline ko04750 & $\begin{array}{l}\text { Inflammatory mediator } \\
\text { regulation of TRP } \\
\text { channels }\end{array}$ & $\begin{array}{l}\uparrow \text { MAP2K6, CD74-Ntrk1, TRPV4, PRKACA, PIK3CB, } \\
\downarrow \text { PLA2s, PRKCH, PPP1CC, PKC } \varepsilon\end{array}$ \\
\hline ko00120 & $\begin{array}{l}\text { Primary bile acid } \\
\text { biosvnthesis }\end{array}$ & $\begin{array}{l}\uparrow \text { CYP46A1, FLJ93299 } \\
\text { CYP7B1 }\end{array}$ \\
\hline ko00740 & Riboflavin metabolism & $\begin{array}{l}\uparrow \text { ACP1 } \\
\downarrow \text { RFK, ACP2 }\end{array}$ \\
\hline ko03020 & RNA polymerase & $\begin{array}{l}\uparrow \text { POLR3K, POLR2I, FLJ92093, RNAP, POLR2L } \\
\downarrow \text { POLR2G, FLJ54187 }\end{array}$ \\
\hline ko04913 & Ovarian steroidogenesis & $\begin{array}{l}\uparrow \text { PRKACA } \\
\downarrow \text { LDLR, PLA2s, PTGS2 }\end{array}$ \\
\hline ko03015 & $\begin{array}{l}\text { mRNA surveillance } \\
\text { pathway }\end{array}$ & $\begin{array}{l}\uparrow \text { mRNA-capping enzyme } \\
\downarrow \text { PPP1CC }\end{array}$ \\
\hline ko03008 & $\begin{array}{l}\text { Ribosome biogenesis in } \\
\text { eukaryotes }\end{array}$ & $\downarrow$ RIOK2, DKFZp68602396 \\
\hline ko04144 & Endocytosis & $\begin{array}{l}\uparrow \text { RUFY1, FOLR1, WASHC1 } \\
\downarrow \text { LDLR, SPG20, WASHC2C, FLJ33900, SNX32, } \\
\text { CHMP4C, FLJ96001 }\end{array}$ \\
\hline ko05321 & $\begin{array}{l}\text { Inflammatory bowel } \\
\text { disease (IBD) }\end{array}$ & $\begin{array}{l}\uparrow \text { STAT1, STÄT } \\
\downarrow \text { TLR5, IL1A }\end{array}$ \\
\hline ko00760 & Nicotinate and & $\uparrow$ NNMT, NADK2, NT5C3B \\
\hline & $\begin{array}{l}\text { nicotinamide } \\
\text { metabolism }\end{array}$ & $\downarrow$ NT5E \\
\hline ko04630 & $\begin{array}{l}\text { Jak-STAT signaling } \\
\text { pathway }\end{array}$ & $\begin{array}{l}\text { } \text { FHL1, STAT1, CREBBP, OSMR, FLJ12419, STAT, } \\
\text { PIK3CB }\end{array}$ \\
\hline ko04514 & $\begin{array}{l}\text { Cell adhesion molecules } \\
\text { (CAMs) }\end{array}$ & $\begin{array}{l}\uparrow \text { ITGA4, FLJ77845, ALCAM, MPZL1, NECTIN1, GLG1, } \\
\text { FLJ54854 } \\
\downarrow \text { CD274 }\end{array}$ \\
\hline
\end{tabular}

\section{Figures}


C

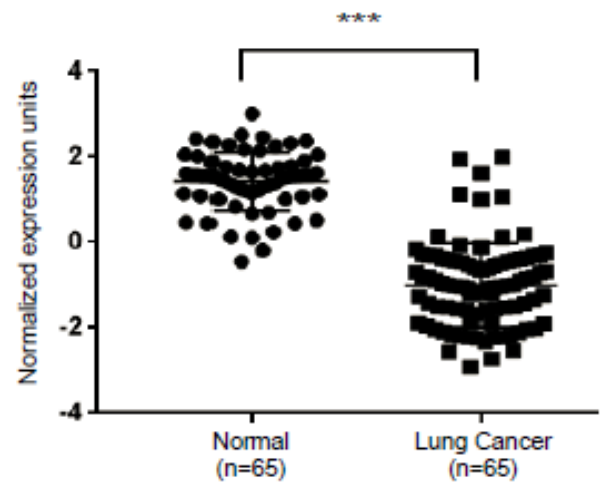

Hou Lung

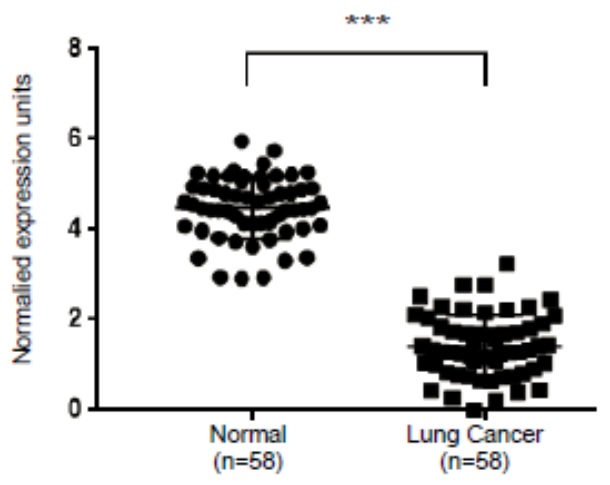

Selamat Lung

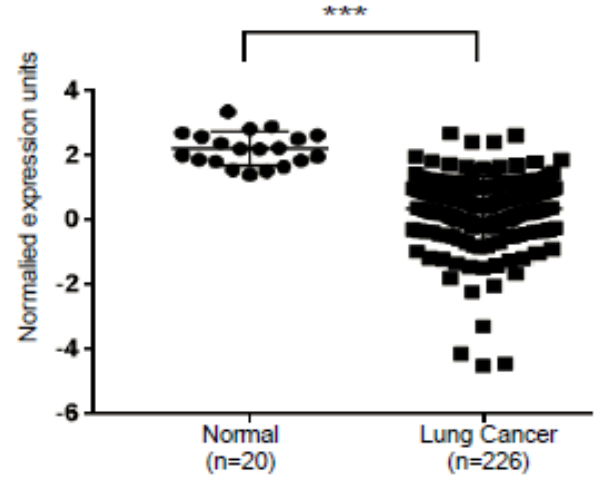

Okayama Lung

Figure 1

Plac9 is repressed in LCs. Expression of Plac9 in LCs and corresponding normal tissues from three independent LC studies (Hou Lung, Selamat Lung, and Okayama Lung, in A-C, respectively) were obtained from Oncomine database and plotted individually. $\left({ }^{*} p<0.05, * * p<0.01\right.$, *** $\left.p<0.001\right)$.

A

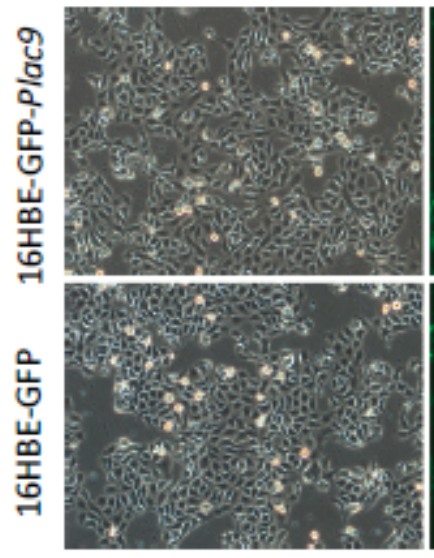

$100 x$
$\mathrm{B}$

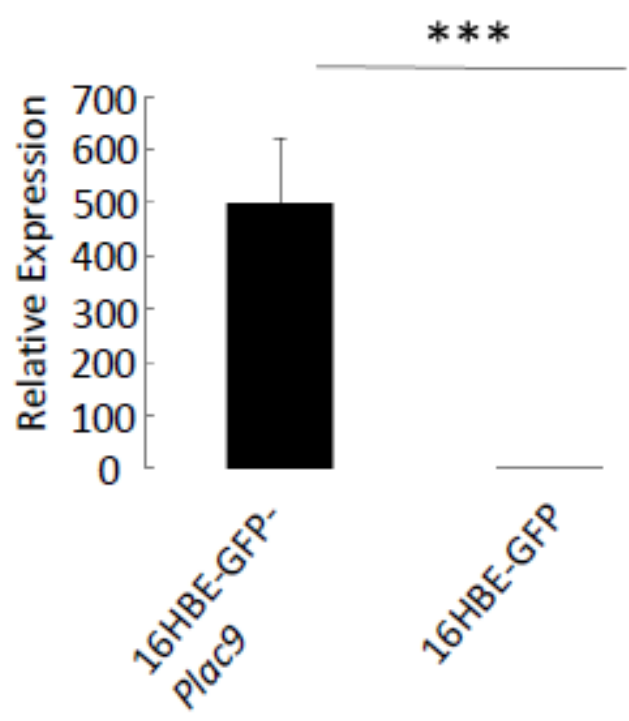

B

kDa

Plac9

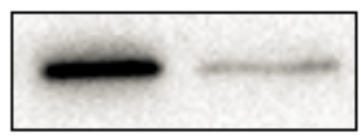

19

$\beta$-actin

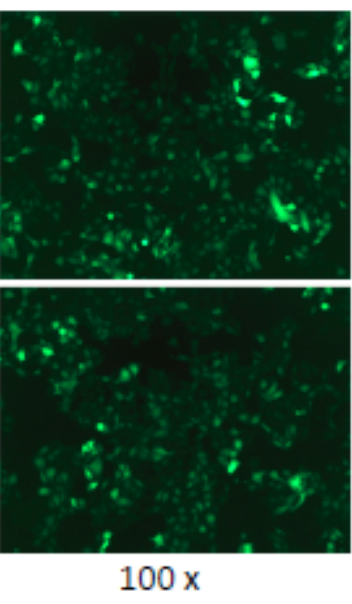

C

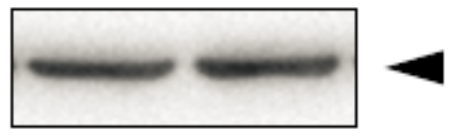

43

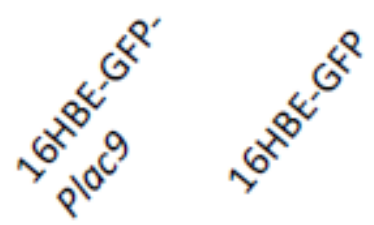




\section{Figure 2}

Construction of stable Plac9-expressing 16HBE cells via lentiviral transduction. (A) The human lung cell line 16HBE used to generate stable cell lines expressing GFP (16HBE-GFP) or both GFP and Plac9 (16HBE-GFP-Plac9). Detection of GFP via fluorescence microscopy in stable cell lines 16HBE-GFP-Plac9 and 16HBE-GPF (green, GFP; $\times 100$ view). Left panel: bright sight. Right panel: dark sight. (B) Quantitative PCR analysis of Plac9 expression showing overexpression of Plac9 mRNA in the stable cell line compared to the control line stably transfected with GFP-expression vector $(* p<0.05, * \star p<0.01$, *ᄎ* $p<$ 0.001). (C) Western blot analysis showing overexpression of Plac9 protein in the stable cell line 16HBEGFP-Plac9 compared to the control. The blots were clopped to improve the presentation. The uncropped blots were shown in Figure S4A-B.

A

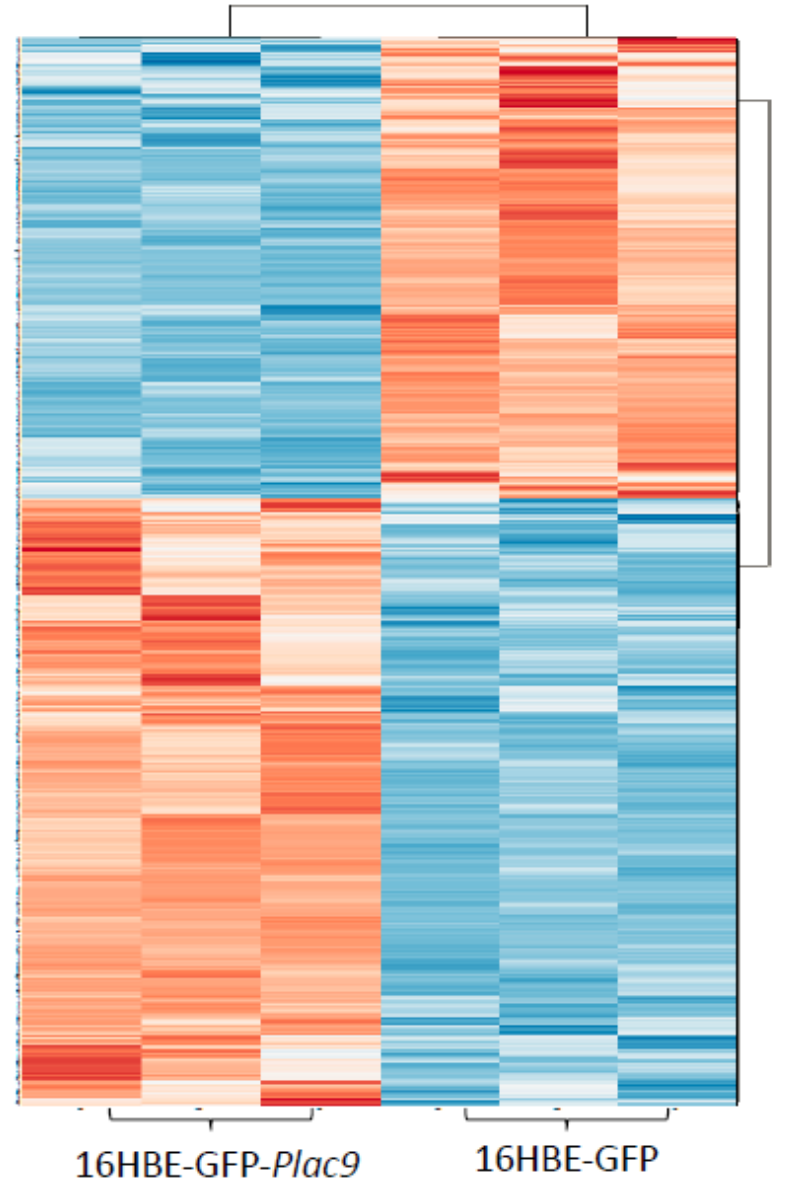

B
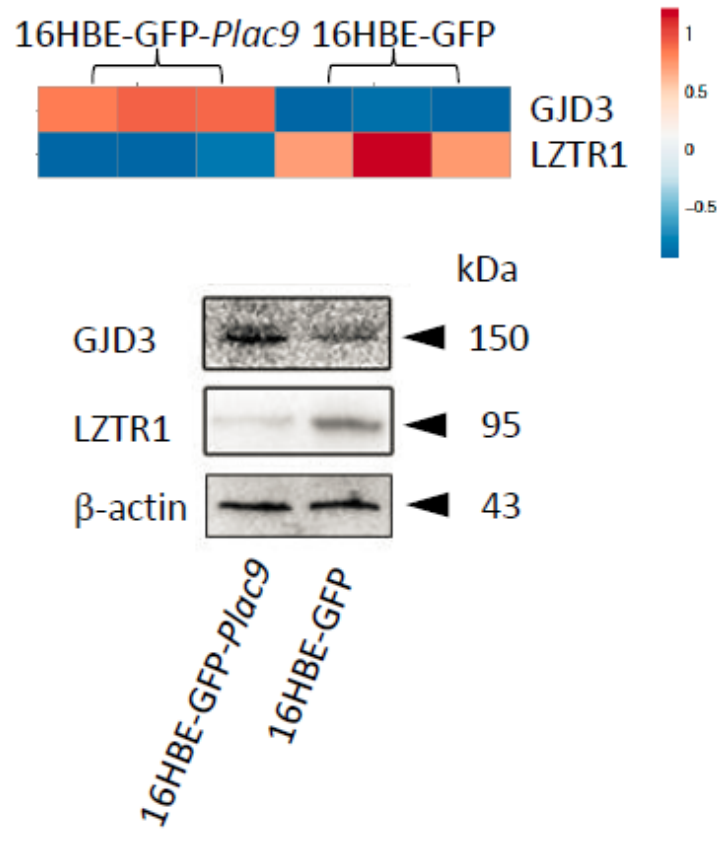

\section{Figure 3}

Global identification of proteins regulated by Plac9 overexpression.(A) Heatmaps of the 714 differentially expressed proteins as identified by iTRAQ in the Plac9-overexpressing line compared to the control line stably transfected with GFP-expression vector. Three replicates were presented for each cell line. Bar color represents a logarithmic scale from -1.5 to 1.5. (B) Independent validation of two differentially expressed proteins (GJD3 and LZTR1) identified by iTRAQ by western blot analysis. Total proteins were isolated from the two cell lines (16HBE-GFP-Plac9 and 16HBE-GFP) for western blot analyses with antibodies 
against GJD3, LZTR1, and the control was $\beta$-actin. The blots were clopped to improve the presentation. The uncropped blots were shown in Figure S4C-E.

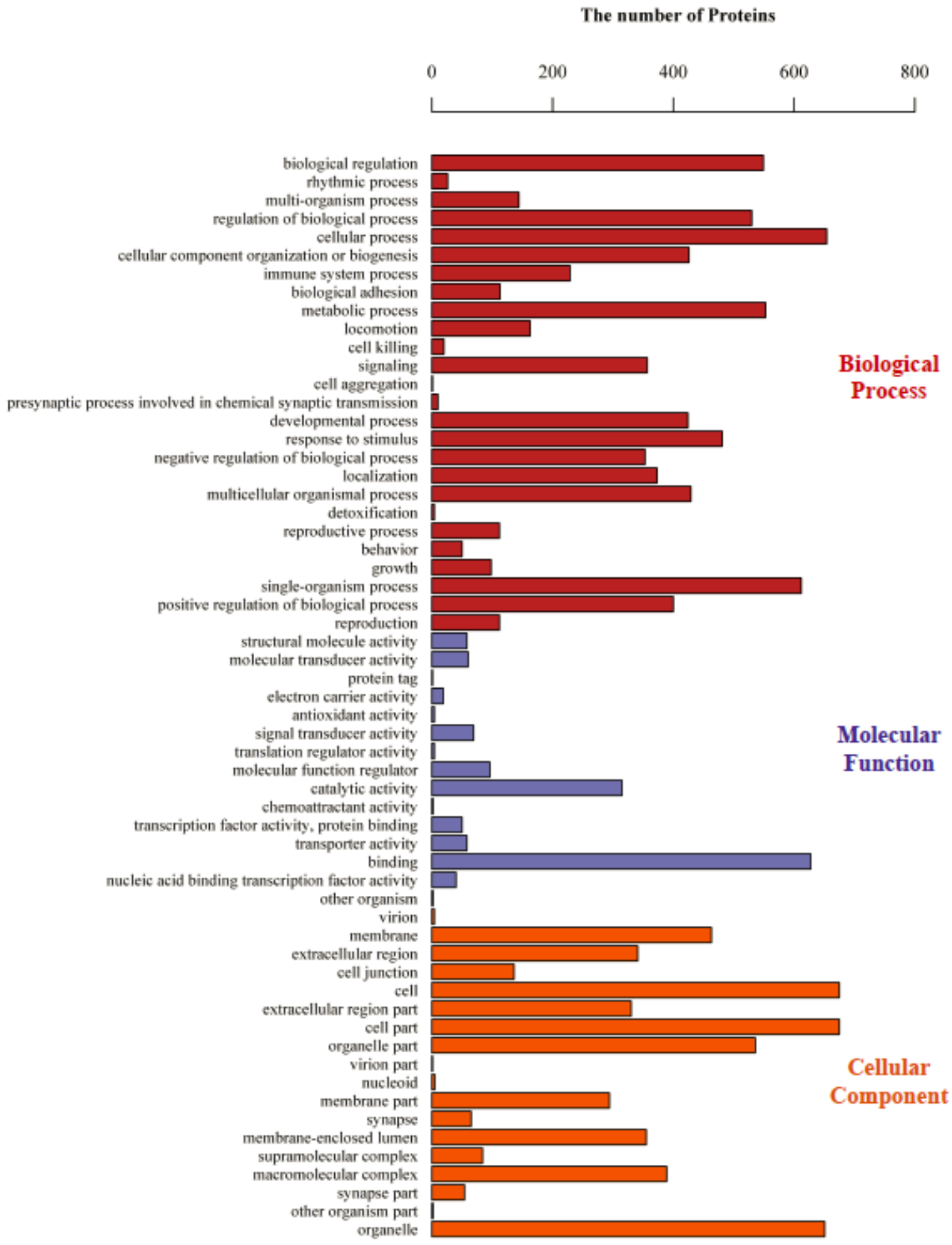

\section{Figure 4}

Gene Ontology (GO) classifications of the differentially expressed proteins. Shown are number of proteins involved in each of the biological process, cellular component and molecular function terms, which could be respectively classified into 26,15 , and 18 subcategory groups, respectively. 


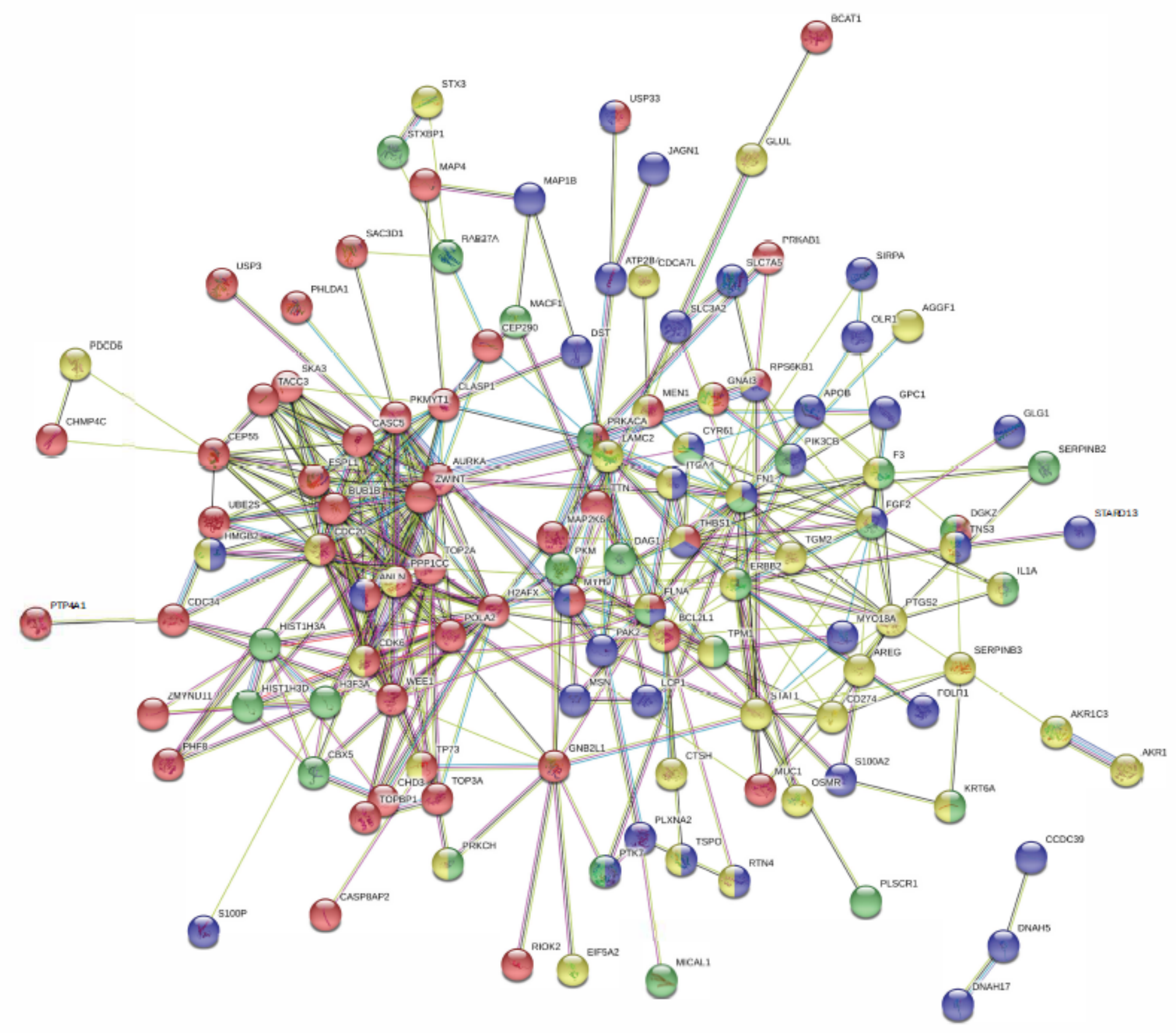

Figure 5

STRING protein-protein interaction network for the 138 proteins involved in cell proliferation, cell cycle and cell migration. Network of the interactions among 138 regulated proteins involved in cellular processes. Network nodes represent proteins. A protein/node may be filled with up to 4 different colors. Yellow represent this protein involved in cell proliferation; Red represent this protein involved in cell cycle; green represent this protein involved in wound healing; blue represent this protein involved in cell motility. The minimum required interaction score was medium confidence (0.400). The structure previews of proteins were displayed inside nodes. All the disconnected nodes in the network were hided. The details of this figure were listed in Table S5. 


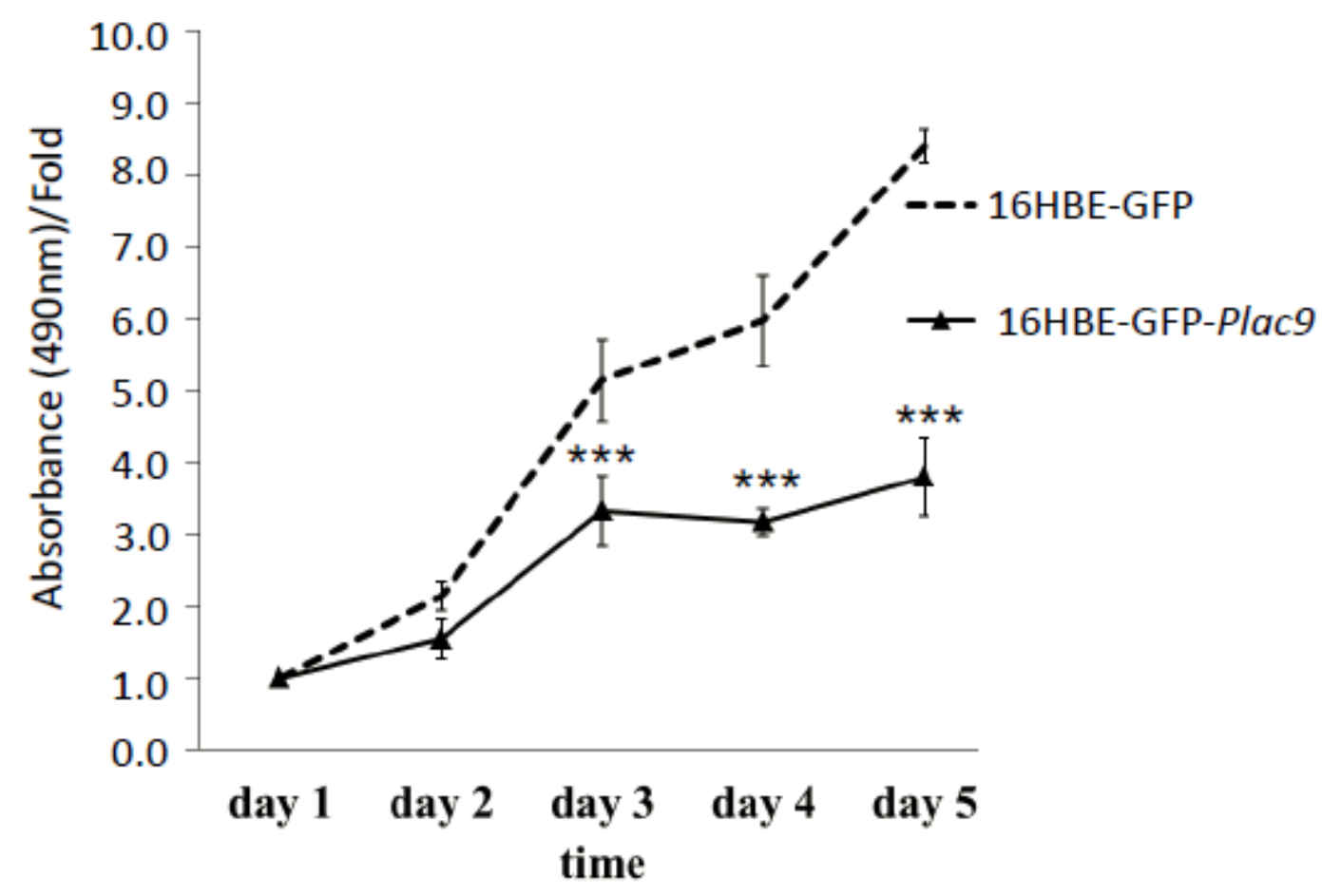

B 16HBE-GFP-Plac9

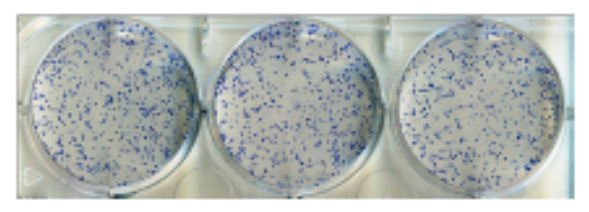

16HBE-GFP

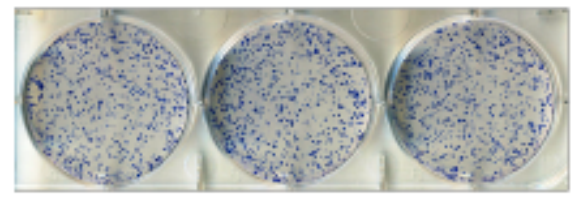

C

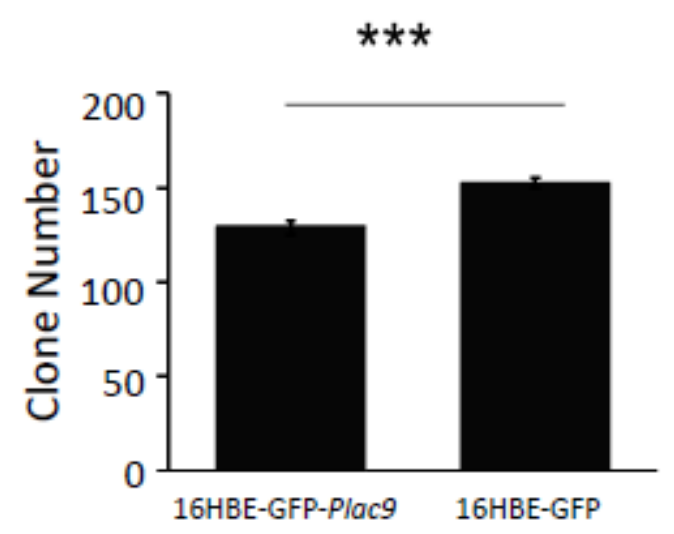

Figure 6

Overexpression of Plac9 inhibits cellular proliferation and colony formation. (A) Overexpression of Plac9 inhibits cell proliferation. 16HBE-GFP-Plac9 and the control line 16HBE-GFP were cultured and cell number was measured daily for 5 days, by measuring the absorbance of the cell culture at $490 \mathrm{~nm}$ with the value at staring point (day 1 ) set to $1 .(B, C)$ Overexpression of Plac9 inhibits colony formation. 16HBE-GFP-Plac9 and the control line 16HBE-GFP were cultured in vitro for 2 weeks to assay for colony formation (B) and the number of colonies/plate were quantified (C). (* $\left.p<0.05,{ }^{\star *} p<0.01,{ }^{\star *} p<0.001\right)$. 
A

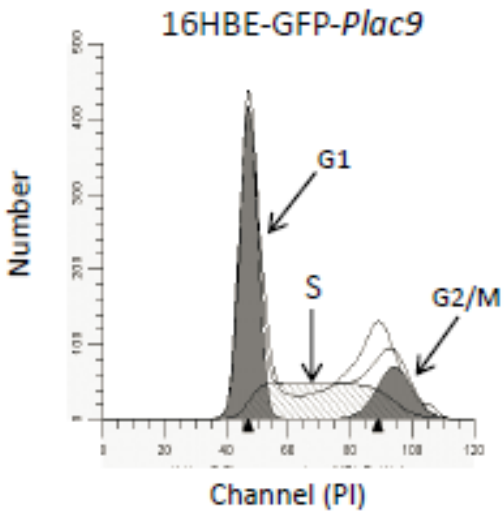

B

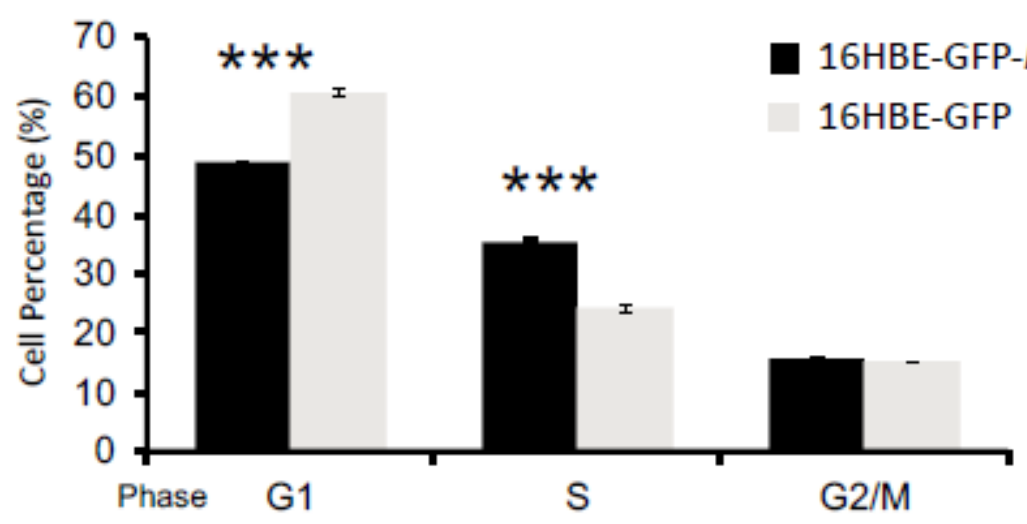

C

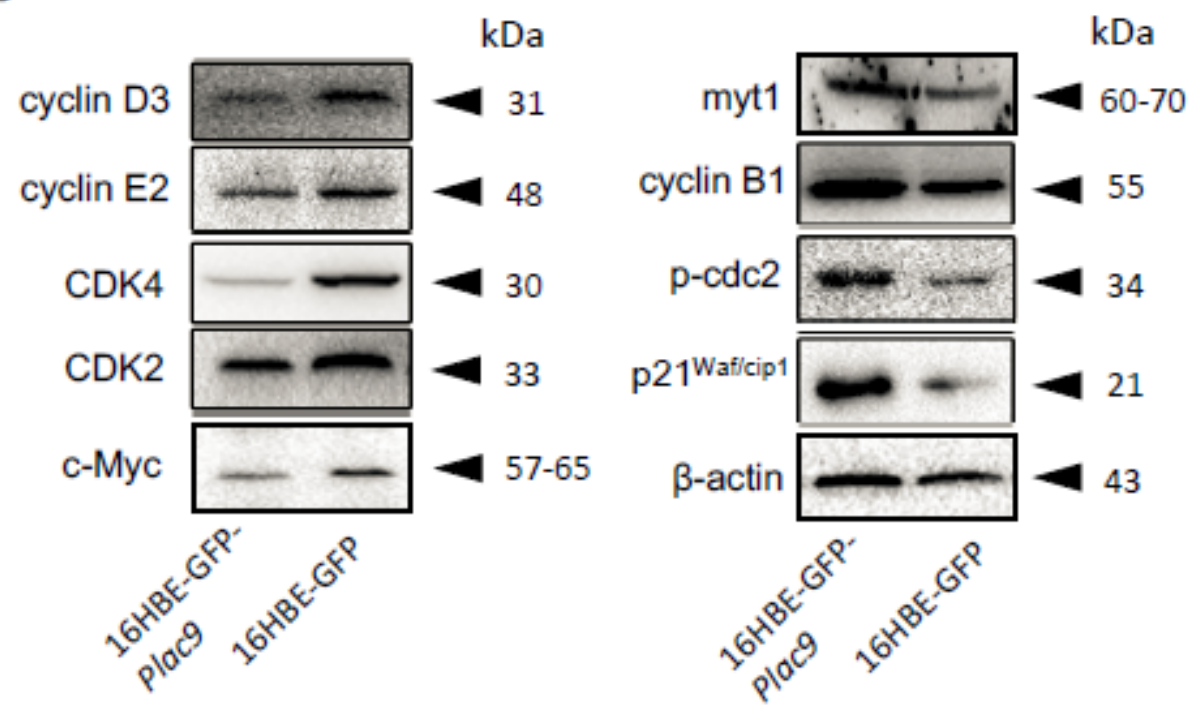

\section{Figure 7}

Overexpression of Plac9 alters cell cycle distribution. (A, B) Overexpression of Plac9 increases the cell population in S phase, while reduces the number of cells in $\mathrm{G} 1$ phase. 16HBE-GFP-Plac9 and control 16HBE-GFP cells were incubated with PI and analyzed by flow cytometry (A) and quantified (B). (C) Plac9 overexpression alters the expression of the cell cycle proteins. The total proteins of 16HBE-GFP-Plac9 and the control line 16HBE-GFP were isolated for Western blot analysis of cell cycle-related proteins. 
Representative blots from three experiments with similar results. The blots were clopped to improve the presentation. The uncropped blots were shown in Figure S4F-O.

A
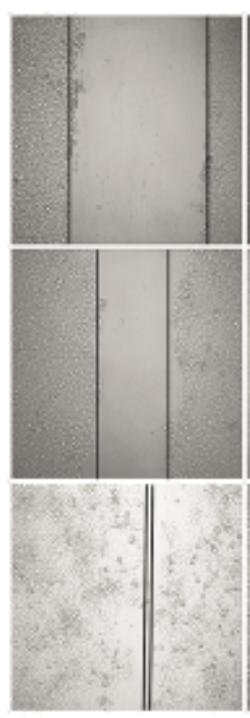

16HBE-GFP-Plac9

16HBE-GFP

C

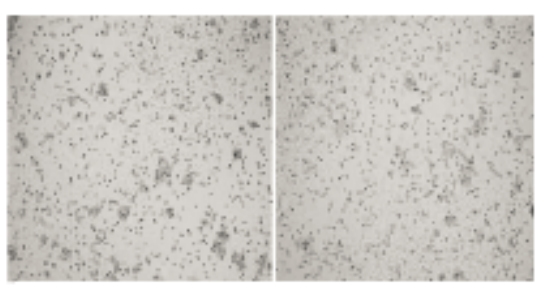

16HBE-GFP-Plac9

16HBE-GFP

$\mathrm{E}$

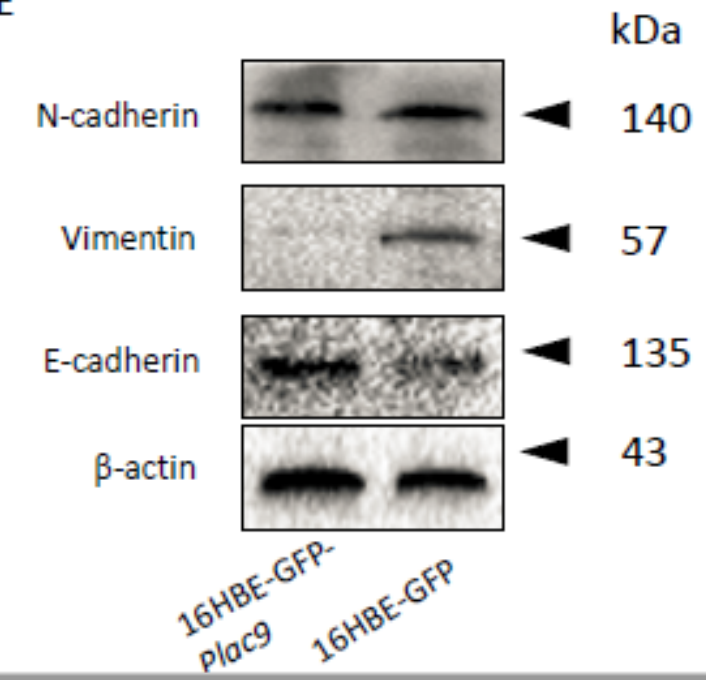

B

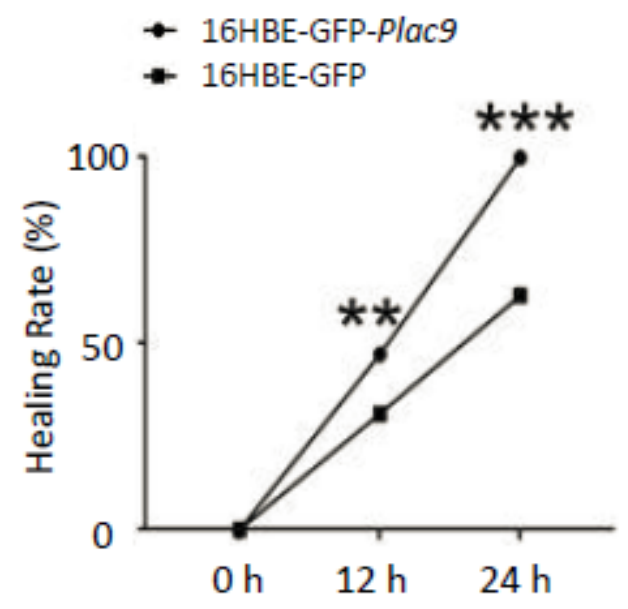

D

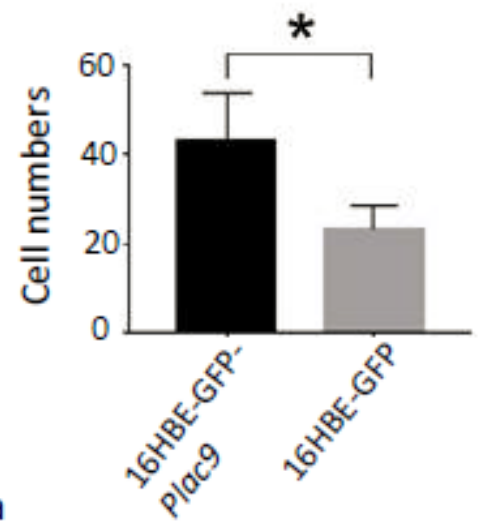

\section{Figure 8}

Overexpression of Plac9 enhances cell migration. (A, B) Plac9 increases cell motility in a wound-healing assay. Plac9 overexpressing stable cell line (16HBE-GFP-Plac9) and the control line 16HBE-GFP were cultured for 0,12 or $24 \mathrm{~h}$ in the wound-healing assay (A). The wound healing rate for 16HBE-GFP-Plac9 
was $42.01 \otimes 5.05 \%$ and $85.93 \otimes 7.56 \%$ at $12 \mathrm{~h}$ and $24 \mathrm{~h}$, respectively, while for $16 \mathrm{HBE}-\mathrm{GFP}$, it was $29.28 \mathrm{\square}$ $1.76 \%$ and $56.64 \otimes 5.75 \%$ at $12 \mathrm{~h}$ and $24 \mathrm{~h}$, respectively (B). ( $\left.{ }^{*} p<0.05,{ }^{*} p<0.01, * * \star p<0.001\right) .(C, D)$ Plac9 increases cell invasion. Plac9 overexpression stable cell line (16HBE-GFP-Plac9) and the stable control line (16HBE-GFP) were cultured for 48 hours in the transwell cell invasion assay (C) and quantified (D). $\left.{ }^{*} p<0.05,{ }^{*} p<0.01,{ }^{* *} p<0.001\right)$. (E) Plac9 alters the expression of cell migrationrelated proteins. Total proteins of Plac9 overexpressing stable cell line (16HBE-GFP-Plac9) and the control line (16HBE-GFP) were isolated for Western blot analysis. The blots were clopped to improve the presentation. The uncropped blots were shown in Figure S4P-S.

\section{Supplementary Files}

This is a list of supplementary files associated with this preprint. Click to download.

- TableS1.xIsx

- TableS2.xIsx

- TableS3.xIsx

- TableS4.xIsx

- TableS5.xIsx

- SIFigureLegends.pdf

- FigureS1.pdf

- Figures2.pdf

- Figures3.pdf

- Figures4.pdf 